\title{
Social capital and risk and protective behaviors: a global health perspective
}

This article was published in the following Dove Press journal:

Adolescent Health, Medicine and Therapeutics

17 December 201I

Number of times this article has been viewed

\section{Linda M Kaljee \\ Xinguang Chen}

Pediatric Prevention Research Center, The Carmen and Ann Department of Pediatrics, Wayne State University, Detroit, MI, USA
Correspondence: Linda M Kaljee Pediatric Prevention Research Center, The Carmen and Ann Adams Department of Pediatrics, Wayne State University, Hutzel Building, Suite W534, 4707 St Antoine Street, Detroit, MI 4820I, USA

Tel + I 301873 I203

Email lkaljee@med.wayne.edu
Abstract: Social capital and health research has emerged as a focus of contemporary behavioral epidemiology, while intervention research is seeking more effective measures to increase health protective behaviors and decrease health-risk behaviors. In this review we explored current literature on social capital and health outcomes at the micro-, mesa-, and macro-levels with a particular emphasis on research that incorporates a social capital framework, and adolescent and young adult engagement in risk behaviors. These data indicate that across a broad range of socio-cultural and economic contexts, social capital can affect individuals' risk for negative health outcomes and their engagement in risk behaviors. Further research is needed which should focus on differentiating and measuring positive and negative social capital within both mainstream and alternative social networks, assessing how social constructions of gender, ethnicity, and race - within specific cultural contexts - mediate the relationship between social capital and risk and/or protective behaviors. This new research should integrate the existing research within historical socioeconomic and political conditions. In addition, social capital scales need to be developed to be both culturally and developmentally appropriate for use with adolescents living in a diversity of settings. Despite the proliferation of social capital research, the concept remains underutilized in both assessment and intervention development for adolescents' and young adults' engagement in risk behaviors and their associated short- and long-term poor health outcomes.

Keywords: social capital, global health, risk behaviors

\section{Social capital: an overview}

Since the mid-1990s, social capital research has increasingly become a part of the academic landscape, crossing a broad range of disciplines including sociology, anthropology, economics, political science, criminology, and public health. ${ }^{1}$ Early theoretical and empirical work regarding the relationships between society and individuals and the roles of social networks at individual, community and national levels, eg, Durkheim, ${ }^{2}$ are considered precursors to the concept of social capital. In the 1980s, the writings of Bourdieu $^{3}$ and Coleman ${ }^{4}$ systematically defined the term and fueled academic interest in the application of the concept. Social capital as defined by Bourdieu and Wacquant ${ }^{5}$ (p119) is "the sum of the resources, actual or virtual, that accrue to an individual or a group by virtue of possessing a desirable network of more or less institutionalized relationships of mutual acquaintance and recognition" [cited in Halpern 2005]. Social capital is conceptualized and measured in terms of social networks, shared norms, objectives and sanctions, and mutual trust. Social capital facilitates individual and community actions but an individual's social capital is tied to his/her membership within a group. ${ }^{6}$ 
Social capital can be further divided into three primary forms of relationships. Two of these forms of relationships (bonding and bridging) are more or less 'horizontal' connecting people from similar economic backgrounds. As described by Putnam ${ }^{7}$ (p22), "Some forms of capital are, by choice or necessity, inward looking and tend to reinforce exclusive identities and homogenous groups (bonding) ... other networks are outward looking and encompass people across diverse social cleavages (bridging) ..." The third type of relationship is 'linking social capital' which is defined by Szreter and Woolcock ${ }^{6}(\mathrm{p} 655)$ as "... norms of respect and networks of trusting relationships between people who are interacting across explicit formal or institutionalized power or authority in society." What distinguishes social capital from individual social networks is the integrated yet 'functional equivalence' of multiple levels of analysis - micro-level (individual), meso-level (community/group), and macrolevel (national). ${ }^{1}$ These integrated multi-level components are one of the major challenges in social capital research in terms of disintegrating the effects of individual social networks from the effects within the wider community.

Social capital can be used for 'pro-social' and 'anti-social' activities. ${ }^{8}$ Social capital in terms of trust and reciprocity can be either inclusive or exclusive. ${ }^{6}$ This has been evident most often in the field of criminology, where negative social capital (networks with shared norms in contradiction to mainstream society) can contribute to an individual's engagement in illegal activities, as well as an individual's isolation from broader familial, peer, and other social connections. For adolescents, such negative social capital can include engagement in peer groups where alcohol and/or drug use is routinely a part of socialization activities. At a more extreme level, homeless youth or those youth who are part of gangs may derive significant social and economic support through alternative bonding networks. ${ }^{9}$

In this paper, we want to explore current literature on the relationship between social capital and health outcomes with an emphasis toward explicating the potential role of social capital in adolescents' and young adults' engagement in risky behaviors, and their increased likelihood of negative health outcomes.

\section{Social capital and health}

There is extensive literature that focuses on social capital and its relationship to the individual's and the population's health. ${ }^{1,10-12}$ In a study of 45 countries, good self-reported health ratings were positively associated with greater social capital and negatively associated with income inequality across a diversity of countries. ${ }^{13}$ At the individual or microlevel, effects of social capital on adolescents' and young adults' health outcomes are both short- and long-term. In relation to the former, adolescents are at a stage of development whereby they are becoming decreasingly dependent on family and increasingly involved in the establishment of peer networks. These peer networks can have significant sway over behaviors and can result in both positive and negative health outcomes. In the long-term, adolescents' familial and peer networks can potentially influence future establishment of social networks and resulting social capital, which can affect health outcomes later in life. ${ }^{14}$ Previous positive supportive relationships, eg, parent-child, are also considered a contributor to better lifelong health. ${ }^{1,15} \mathrm{~A}$ key aspect of this micro-level social capital is the 'positive' nature of the relationships - as close relationships with abusive, emotionally impaired individuals can result in negative health outcomes. ${ }^{16}$ In Cattell's ${ }^{17}$ ethnographic study in East London, residents in 'socially excluded' networks (small number of groups with few members), such as women with abusive or controlling partners and young single mothers, were more likely to express feelings associated with negative health outcomes.

At the meso-level, the broader question is whether or not communities, spaces, neighborhoods, and organizations affect health independent of an individual's support network. More specifically, is there an additive effect by which mesolevel social capital can mediate micro-level social networks to decrease likelihood of negative health outcomes and/ or increase likelihood of positive outcomes? One area of research has looked at "group density effect", which suggests that ethnic groups living together within an enclave have better health outcomes than those individuals from the same ethnic group living within a mixed ethnic neighborhood..$^{14,18}$ In addition, migration out of ethnic neighborhoods and/or gentrification can create disintegration of important social networks and associated capital in urban communities. ${ }^{19}$ In a study of Hispanic and non-Hispanic adolescents, self-reported perceived health outcomes among Hispanic respondents were more closely associated with variations in reported social capital. This greater tie between social capital and perceived health among the Hispanic youth may be related to general higher level of local institutional selfcontainment with extended family, community businesses, etc. Within this neighborhood context, non-engagement or exclusion from networks may have a more significant effect on residents..$^{14}$

While not all research on group density effect has pointed to positive health outcomes, these ethnic neighborhoods 
potentially provide a level of protection against stress, including stigmatization and racism. In Carol Stack' ${ }^{20}$ work in a low-income black community in the 1970s, she describes a network of actual and fictional kin relationships which provided social, emotional, and economic support. These concepts of 'group density effect' and community-level networks are in contrast and, in some instances, in response to the significant body of work grounded in a 'culture of poverty' or 'underclass' perspective that emphasizes links between poverty and feelings of marginality and dependence..$^{21,22}$

At the macro-level of social capital, the primary question is whether individuals residing in certain regions or nations experience better health outcomes and greater wellbeing beyond what would be anticipated from individuals' positive social networks. While it is generally assumed that a link exists between economic prosperity and well-being, Helliwel1 ${ }^{23}$ describes 'negative externality', in which higher income at the aggregate level results in lower life-satisfaction. In a study of 30 districts in Saskatchewan, Canada, levels of mortality at the population level were negatively associated with social capital and positively associated with income inequality - a potential indicator of broader social inequalities which could affect social capital development. ${ }^{24}$ In a preliminary study in the US, lower levels of social capital were a predictor for gonorrhea and syphilis, and social capital and income inequality predictors for AIDS case rates. ${ }^{25}$

Lower life-satisfaction, within a context of social inequalities, could be relevant to the health outcomes of young adult rural Chinese migrant workers. In a transitional economy such as China's, ${ }^{26}$ those outside of the urban spheres of wealth and consumption experience real and perceived inequalities, internalized and externalized stigma, and high stress trying to meet basic needs for self and family. ${ }^{27}$ As in Wilkinson's work on social capital and inequality in transitional economies, those living in the lower socioeconomic groups in an increasingly hierarchical society will experience levels of anxiety that ultimately affect health outcomes. ${ }^{28}$ Increasing non-egalitarian distribution of resources may also precipitate greater negativity and mistrust between groups ${ }^{29}$ decreasing likelihood of the development of the bridging and linking types of social capital.

\section{Risk and protective behaviors and social capital}

Health risk can be defined as a disease precursor associated with a higher-than-average morbidity or mortality rate. These risks can be a product of an individual's biology/genetics, behaviors, or environment. In terms of behavioral risks, individuals or groups might be perceived as at risk of engaging in a particular behavior or, as a result of already engaging in a behavior, at risk for a negative health outcome. ${ }^{30}$ 'Problem behaviors' are those actions which are undesirable by social and/or legal norms of conventional society and legal authorities and elicit some form of social control. Explanatory variables for engagement in these behaviors include the environmental system - social controls (sanctions), role models, and social support, and personality systems - values, expectations, beliefs, attitudes (social norms). ${ }^{30}$ While certain sanctioned behaviors are more or less universal, eg, stealing, many are culturally and socially bound. Thus, adolescents' or young adults' engagement in a pre-marital sexual relationship might be considered immoral and stigmatizing, ${ }^{31}$ or even illegal in some socio-cultural contexts. ${ }^{32}$ However, in other socio-cultural contexts only certain forms of pre-marital sexual relationships may be considered problematic, eg, transactional sexual relations. Behaviors that are socially and legally sanctioned in one social group may result in stigmatization and discrimination in relation to an individual's or a group's behaviors (and therefore their health outcomes) - most notably HIV (Human Immunodeficiency Virus), but also certain cancers, obesity-related diseases, and historically and in low-resource regions, diseases associated with poverty and poor sanitation. ${ }^{33-36}$

Social capital research and risk behaviors are particularly salient in relation to adolescent health. Adolescence is a period of socialization through experimentation and risk-taking. Tobacco use among adolescents is tied to similar behaviors within peer networks with a high degree of homogeneity of cigarette smoking. ${ }^{37}$ Alcohol use and abuse during mid- and late-adolescence is associated with negative neurological and cognitive development, but also with positive social changes and life transitions, eg, entering university, ${ }^{38,39}$ which is accompanied by the establishment of new peer networks. Globally, sexual initiation occurs for most individuals during adolescent years. ${ }^{40}$ Sexually transmitted infections including HIV/AIDS (acquired immunodeficiency syndrome) disproportionately affect adolescents and emerging adults. ${ }^{41}$ In a study of 14 - to 19 -year-old females in the US, $37.7 \%$ of sexually active participants had a sexually transmitted infection (human papillomavirus, gonorrhea, chlamydia, C trachomatis infection and/or herpes simplex virus type 2). ${ }^{42}$ Adolescent vulnerability to sexually transmitted infections has been linked to sexual networks ${ }^{43}$ which may also provide other forms of social and economic support. Adolescent women in poverty and with limited access to resources can become involved in transactional sex through familial and peer social networks. ${ }^{44}$ 
In terms of social capital research, there are several issues of importance related to conceptualization of health risk. The distinction of being at risk for a behavior or at risk for a particular disease affects the framework for research and analysis - the former requires social capital to be viewed as a mediator for primary prevention and is associated with notions of social norms and sanctions. In many instances this approach of social capital and primary prevention may be more closely aligned to existing social capital research in the field of criminology and deviant behaviors, especially in relation to engagement (or risk of engagement) in activities such as illegal drug use.

The latter is better conceptualized as secondary prevention or, practically, access to treatment and other health resources. Social capital can also be associated with disease severity and in some instances research may be more concerned with biological responses, eg, stress, anxiety, the consequences of these responses on disease vulnerability or severity, and the potential mediating effects of social capital.

To further consider the role of both negative, (or alternative) and positive social capital in relation to health risk behavior, we want to frame potential mechanisms at the micro-, mesa-, and macro-level. These mechanisms should be considered as integrative, and perhaps in some instances, contradictory, and in all instances need to be contextualized within extant and historical socio-cultural and politicaleconomic conditions. (Halpern ${ }^{1}$ [p119] notes: "The use of the term 'negative social capital' ... is problematic in a wider context as it rests on a post hoc judgment from a particular point of view as to what is negative." We will therefore employ the term 'alternative' social network to describe those networks which might exist outside the larger mainstream social structures and networks. Such alternative networks can apply to groups engaged in illegal activities, eg, gangs, but could also apply to social or political activist groups, or those engaged in non-biomedical health systems.)

As Table 1 shows, at the micro-level alternative bonding networks can exist among a group of peers engaged in risk behaviors. This mechanism draws from research in criminology in which offenders associate with one another in an alternative social network with its own norms and sanctions. ${ }^{9}$ In terms of risk behavior however, "alternative" networks may vary based on internal and external factors. Research among IDUs suggests that social network density and size, perceptions of risk, as well as external stigmatization, economic deprivation, and isolation from mainstream networks and institutions may reinforce engagement in HIV risk behaviors. ${ }^{19,45,46}$ From a multi-method study in Brooklyn, Friedman et $\mathrm{al}^{47}$ present data which indicates that despite low levels of trust, low-income residents, including drug users and dealers, utilize social and communication networks to reduce risk of HIV infection. These mechanisms include kin-networks whereby individuals learn about the negative consequences of risk behaviors from the experiences of family members, negotiating space between neighborhood residents and those engaged in the drug trade (users and dealers), and using the encouragement of others within social networks to protect themselves.

Social capital and engagement in risk behaviors can also be part of mainstream networks of peers such as alcohol use and sexual risk behavior among men. While extensive literature exists regarding social norms and alcohol consumption,

Table I Overview of micro-level, meso-level, and macro-level components of social capital in relation to engagement in risk and protective behaviors

\begin{tabular}{|c|c|c|}
\hline & Risk & Protective \\
\hline Micro-level & $\begin{array}{l}\text { Bonding social capital in alternative (deviant) groups } \\
\text { Bonding social capital in mainstream groups with strong } \\
\text { social norms for risk behavior (eg, alcohol consumption) }\end{array}$ & $\begin{array}{l}\text { Bonding social capital in mainstream groups with } \\
\text { strong social norms against risk behavior, or for } \\
\text { engagement in protective behaviors } \\
\text { Bridging and linking social capital between groups } \\
\text { with resources (eg, access to health care, social } \\
\text { services, education) }\end{array}$ \\
\hline Meso-level & $\begin{array}{l}\text { Insular communities - strong bonding social capital, but little } \\
\text { bridging/linking social capital }\end{array}$ & $\begin{array}{l}\text { Communities with greater bridging/linking social } \\
\text { capital to resources } \\
\text { Stable residency patterns and historical connections } \\
\text { (work, socialization) }\end{array}$ \\
\hline Macro-level & $\begin{array}{l}\text { Non-egalitarian societies including transitional countries with } \\
\text { increasingly disparity between income groups } \\
\text { Nations/societies with historically-based ethnic/tribal conflicts } \\
\text { and marginalization and discrimination } \\
\text { Nations/societies with high levels of corruption and low levels } \\
\text { of political-economic transparency }\end{array}$ & $\begin{array}{l}\text { Egalitarian societies with accessibility across } \\
\text { socioeconomic groups to health, social, and } \\
\text { economic opportunities }\end{array}$ \\
\hline
\end{tabular}


particularly in western contexts,${ }^{48}$ there has been much less attention on the potential social capital gained (or lost) as a consequence of men's participation in drinking events. In research in Cambodia among men testing positive for HIV, factors associated with visiting a sex worker included being invited by a friend (88\%) and alcohol consumption (74\%). ${ }^{49}$ In Vietnam, as in other areas in Asia, men drink in social group settings with peers and colleagues, where there are implicit expectations about amounts of alcohol to be consumed and, in some cases, post-drinking engagement with sex workers. ${ }^{50,51}$ Alcohol consumption is a part of the Vietnamese social construction of masculinity, so "a man without alcohol is like a sail without wind". These drinking groups of peers and/or colleagues are important networks for men in terms of work and access to resources. Establishment of these patterns of male peer and collegial drinking are established during late adolescence and early adulthood. ${ }^{51,52}$

Bonding networks within social mainstream groups and organizations can potentially decrease engagement in risk behaviors - however, the positive or negative effects of participation in mainstream network organizations are complex and can lead to seemingly contradictory outcomes. Bartkowski and $\mathrm{Xu}^{53}$ studied US adolescents' use of alcohol, marijuana, and other illicit drugs and its association with their participation in religious and civic/secular organizations. The findings indicate that engagement in religious and civic groups (eg, attendance at services) decreased likelihood of drug use. However, in terms of religious affiliation, internalization of norms did not affect drug use, and association with certain denominations, eg, Catholic, liberal and moderate Protestant increased alcohol consumption.

In a qualitative study of young immigrant Filipino gay men living with HIV/AIDS, Takahashi and Magalong ${ }^{54}$ describe 'disruptive social capital' whereby engagement with mainstream and alternative social groups can both lead to outcomes which increase or decrease health and wellbeing. He states that 'disruptive social capital' focuses on the instabilities and disruptions in the lives of marginalized populations. The Filipino men prior to their HIV diagnosis had two social networks - their mainstream support group of friends and family who were primarily unaware of their sexual identity and their "underground" venue-based network of other gay men. After diagnosis with HIV, the men's experiences varied with some finding support among members of their mainstream network of family and friends, while others experienced stigmatization and isolation. Simultaneously, support from members of their "underground" network both led some men to engage in higher risk behaviors (drug use) while for others the support enabled the men to decrease engagement in risk behaviors.

Research in a South African mining community revealed that young men and women in sports clubs experienced lower prevalence of HIV infection. However, men participating in "voluntary savings clubs" which included social festivals had higher prevalence of HIV infection than those men not participating, and women within these same clubs reported more casual partners. ${ }^{55}$ Another study of young women in Zimbabwe indicated that engagement in social groups decreased risk of HIV and increased safer behavior. However, this data also suggests participants' perceptions of group performance and purpose, and participants' education level affected level of protection. The research found that young women participating in "voluntary savings clubs" and those involved in political party organizations were engaged in less protective behavior, ${ }^{56}$ similar to the results found in South Africa.

Research with 14-35-year-old residents in 750 households in eight villages in South Africa utilized two measurements of social capital and association with HIV risk. Cognitive social capital included perceptions of levels of reciprocity and community support, perceived community solidarity during crisis, and level of participation in collective actions; structural social capital included respondents' group membership and level and intensity of engagement. Male respondents from households with higher cognitive social capital had lower prevalence of HIV, were more likely to report condom use, and were better able to communicate about sexual issues with household members. Higher levels of both cognitive and structural social capital among female respondents improved psychosocial functioning, including communication. While female respondents with higher levels of structural social capital were more likely to report condom use, they had a higher prevalence of HIV. ${ }^{57}$

At the meso-level, characteristics of the community and the individuals' engagement with family and friends are associated with health risks through complex mechanisms that are strongly associated with the historical and the extant contexts of life and work within the communities. Poverty and low-resource neighborhoods have long been linked to increasing engagement in risk behaviors as well as in 'environmental' risks, which affect residents' morbidity and mortality. Cattell's ${ }^{17}$ ethnographic research in two communities in East London showed a typology of networks based on forms and strengths of bonding, bridging, and linking relationships: (1) social exclusive or truncated; (2) homogenous; (3) traditional; (4) heterogeneous; and (5) solidarity. While the latter two types (heterogeneous 
and solidarity) include varying degrees of strength of bonding relationships, they are also inclusive of bridging and/or linking networks that provide connections for those individuals/ groups outside of the immediate neighborhood. Both the homogenous and traditional are strong bonding networks, which provide social support within the socio-cultural and economic confines of the East London communities. These insular networks develop within contexts of history, work opportunities, and local resources - but they can be exclusionary, resulting in limited access to linking networks to external social, health, and economic resources. Cattell's findings echo Stack's ${ }^{20}$ (p124-125) findings in an urban black low-resource community in the US.

\footnotetext{
"Within domestic networks, women and men maintain strong loyalties to their kin, and kin exert internal sanctions upon one another to further strengthen the bond. Attempted social mobility away from the kin network of exchanges and obligations, by means of marriage or employment, involves a precarious risk in contrast to the asylum gained through generosity and exchange. Thus survival demands the sacrifice of upward mobility and geographic movement ...”
}

Caughy et $\mathrm{al}^{58}$ suggest that neighborhood-level wealth is a significant factor in the health benefits of bonding networks. In a study of black communities in Baltimore City, parents with young children in wealthier neighborhoods who had less contact with neighbors experienced higher levels of anxiety and depression; those in poorer neighborhoods with less contact experienced lower levels of anxiety and depression. Research in the Netherlands indicates a strong relationship between residential instability, social cohesion and trust among adults and children, and general health outcomes. The data indicates residential instability is not related to informal social control of, for example, children's behaviors. ${ }^{59}$ The interrelated factors in low-resource communities of neighborhood longevity, residential stability, and population homogeneity are salient to development of more inward-focused bonding networks versus outward-focused bridging and linking networks.

Of particular interest to research on health risk and social capital are displaced communities of refugees and internal and external migrants. Research suggests rural-to-urban migrants in China engage in health risk behaviors (alcohol abuse, engagement in transactional sexual relations), and experience social stigma and psychological distress. ${ }^{60-62}$ A significant source of stress among migrant workers is reported to be their interactions with urban residents. During qualitative interviews, rural migrants describe verbal and non-verbal assaults from individual urban dwellers as well as urban institutions, eg, media. These rural migrants are not only unable to build supportive social networks and reconstruct social capital in the cities where they live and work, but they are also faced with day-to-day experiences of discrimination, mistrust, and stigma. These migrant workers live in large neighborhoods that are socially and physically isolated. Within these neighborhoods, they may have a reprieve from the negativity which confronts them in their interactions with urban residents and an opportunity to develop migrant-tomigrant networks. However, the migrant communities are populated by transient individuals who remain emotionally and socially tied to their original villages. These migrant networks and the protection afforded within these neighborhoods are limited in terms of rural migrants' access to information, social and health resources, and economic opportunities. ${ }^{27}$ From a social capital perspective, migrant workers have bonding social capital within the urban migrant enclaves and with peers and kin in their home villages but lack bridging and linking social capital with members of urban-based groups and institutions.

At a macro-level, historical contexts of inequalities are often not acknowledged or accounted for in social capital research. Thus colonial legacies of "divide and rule", which can be maintained by elite rulers in post-colonial countries, can have profound effects on access to resources which are tied to one's ethnic, tribal, and/or residential area. ${ }^{63}$ Tribalization can lead to strong exclusionary bonding social networks, with some groups having bridging/linking social capital to economic, political, and social sources of wealth, while other groups are marginalized. Furthermore, transparency (or lack thereof) of governmental resource distribution further confounds issues of social cohesion and trust within and between groups. Within societies or nations with unequal distribution of resources, adolescents and young adults in marginalized populations experience less bridging and linking social capital, greater likelihood of engagement in risk behaviors, and associated poorer health outcomes.

\section{Measurement of social capital}

Despite the great potential to advance health and behavior research through social capital research, the lack of reliable and valid instruments for social capital measurement presents a significant barrier. ${ }^{67}$ As we have summarized in the first section of the paper, much work has been done to conceptually define social capital. Several measurement instruments have been reported for quantitative research, but the differences in the definition of social capital and the settings for testing these instruments limit their use. In order to advance research 
on the mediating effects of social capital on adolescent and young adult engagement in risk behaviors, there is a need to continue to refine the translation and quantification of social capital concepts.

Large-scale survey studies on social capital and population health are often based on one or two questions, tapping into social participation and trust as a proxy for social capital in general. ${ }^{10,11}$ Given the complexities of both alternative and positive social capital, adolescent and young adult risk behavior and health outcomes, more comprehensive, culturally, and developmentally appropriate instruments are required. The "Adapted Social Capital Assessment Tool" (ASCAT) developed by a team of researchers from the World Bank has been used in cross-country studies. ${ }^{64}$ The assessment's strengths include being relatively short (nine items) and therefore useful for large scale studies, and having been tested in low- and middle-income countries including Ethiopia, India, Peru, and Vietnam. ${ }^{65,66}$ This instrument however has not been adequately adapted for other areas, and respondents experience difficulties understanding such generic groups as "trade union", "community association", "credit/funeral group" that are not salient in all cultural contexts. ${ }^{65}$

In our own work, to facilitate research on social capital, risk behaviors, and health outcomes, we have developed an instrument "Personal Social Capital Scale" (PSCS). ${ }^{67} \mathrm{We}$ operationally defined social capital as "the sum of durable, trustworthy, reciprocal, and resource-rich (wealth, education, social status, and political power) network connections that are used as an asset to empower a society and its members" 67 (p306). The 10-item scale covers bonding and bridging social capital. The bonding sub-scale items include six types of connections (family members, relatives, neighbors, friends, co-workers, and country fellows/old classmates); the bridging sub-scale includes items regarding governmental, political, social-economic, cultural, recreational, and leisure groups and organizations. The instrument has shown adequate reliability (Cronbach alpha $>0.8$ ) and validity (significantly predicted informational, instrumental, and emotional support) within Chinese culture among both migrant and non-migrant populations, but it remains to be tested in other contexts.

\section{Discussion}

The concept and measurement of social capital and its association with engagement in health risk and protective behaviors and risks for negative health outcomes has been explored through individual, neighborhood, community, and national level data. This increasingly expansive literature is comprised of studies based on a diversity of theoretical frameworks and utilizing a range of methodological approaches. To some extent, some of the appeal of social capital might rest in its very broad definition and application at multiple levels. However challenges remain in regards to quantifying the concepts and interpreting the direction of causality in relation to health outcomes. In this paper, we have briefly explored existing literature in an attempt to consider what evidence exists that social capital may affect adolescents' and young adults' engagement in health risk and protective behaviors. We have concluded that there are intriguing suggestions of the highly integrative and dynamic nature of the various levels of social capital, including the complexities of social networks, social norms, and trust in relation to individual behaviors. This existing data suggests several directions for future research that would focus more specifically on the mediating role of social capital on both risk of engagement in behaviors and subsequent risk of poor health outcomes.

- Social capital research needs to differentiate between the two forms of risk (risk of engagement of behavior and risk of poor health outcomes) and how the various levels of social capital can positively and/or negatively mediate the processes associated with these risks. Longitudinal studies with adolescents which follow respondents through adulthood need to be conducted as they will more accurately assess the connection between adolescent social capital, engagement in risk behaviors, and short- and long-term health and well-being. This research needs to be transdisciplinary and utilize theories and methods from fields including criminology, sociology, psychology, and public health.

- As evident from recent studies, social capital can be conceived of as positive and negative in relation to engagement in health risk behavior. This is particularly important in health risk behaviors which may be encouraged within specific contexts in mainstream societies (eg, alcohol consumption). Gregson et $\mathrm{al}^{56}$ suggest a continuum approach from positive to negative - in order to more accurately reflect the complexities within different socio-cultural and political contexts. Global research must be done, focusing on adolescent and young adult engagement in risk behaviors that are socially accepted and the role of social capital in the perpetuation of such behaviors.

- Much of the existing research indicates differential effects of social capital for men and women - however, limited studies have considered social constructs of gender as a starting point. Rather than ad hoc analysis suggesting differences between men and women, more research on risk and social capital needs to originate with the question 
of how the social construction of gender within a specific context mediates the relationships between social capital and risk/protective behaviors. As noted by Takahashi and Magalong, ${ }^{54}$ social capital research is often "blind" to relations of gender, race/ethnicity, and sexual identity.

- While critics of social capital have argued that social networks and relationships cannot overcome the effects of social and economic inequalities, proponents of social capital research need to do more to integrate the preexisting knowledge within existing local, national, and international conditions.

- To date, the vast majority of adolescent risk-reduction interventions are focused on modification of individual attitudes, knowledge, and behaviors. ${ }^{68,69}$ The potential for social capital and social networks as a point for intervention has been posited ${ }^{56}$ However, it is important to differentiate levels of intervention. At the community level, the agencies of change are social groups and networks, with the objective of creating positive social capital to decrease risk of engagement in behaviors and/ or contracting disease. At the structural level, however, change entails the removal of environmental barriers or reinforcement of environmental facilitators to provide positive social capital development. ${ }^{19}$

- Additional research is needed on social capital measurement at various levels. The reported measurement instruments for assessing social capital at the individual level, such as PSCS and ASCAT are useful, although further revision is needed. Instruments must be refined to assess social capital at collective levels, such as social capital possessed by a family, an organization, and/or a community. Instruments used to assess social capital of a nation (eg, trust and social participation) need to be documented for reliability and validity. ${ }^{10,11}$ For global adolescent health research, measurements need to be both culturally and developmentally appropriate and to assess both positive and negative social capital.

\section{Conclusion}

Current literature indicates a strong potential for social capital research as a direction for assessment. It could provide effective means of monitoring adolescent risk and protective behaviors for sexual health and substance use and abuse. Future research needs to both refine and develop reliable and valid tools and methodologies for measuring adolescent social capital. Additional research also needs to understand the mechanisms by which social capital affects health and behavior, and it needs to use the mechanisms as guidance to document association between social capital at the micro- mesa-, and macro-levels, as well as documenting young men and women's engagement in risk behaviors within and across cultural groups.

\section{Acknowledgment}

This study was supported in part by an NIH Research Grant (Award \#: R01 MH086322, PI: Chen X) from the National Institute of Mental Health.

\section{Disclosure}

The authors report no conflicts of interest in this work.

\section{References}

1. Halpern D. Social Capital. Cambridge, UK: Polity Press; 2005.

2. Durkheim E. Suicide. Trans. Spalding JA, Simpson G. Toronto, ON: Free Press; 1979.

3. Bourdieu P. The forms of capital. In: Richardson JG, editor. The Handbook of Theory: Research for the Sociology of Education. New York: Greenwood Press; 1985:241-258.

4. Coleman JS. Social capital in the creation of human capital. Am J Sociol. 1988;94:S95-S120.

5. Bourdieu P, Wacquant LJD. An Invitation to Reflexive Sociology. Chicago, IL: University of Chicago Press; 1992.

6. Szreter S, Woolcock M. Health by association? Social capital, social theory, and the political economy of public health. Int $J$ Epidemiol. 2004;33(4):650-667.

7. Putnam RD. Bowling Alone: The Collapse and Revival of American Community. New York: Simon and Schuster; 2000.

8. Putnam RD. Commentary: 'Health by association': some comments. Int J Epidemiol. 2004;33(4):667-671.

9. Hagan J, McCarthy B. Mean Streets: Youth Crime and Homelessness. Cambridge, UK: Cambridge University Press; 1997.

10. Kawachi I, Kennedy BP, Lochner K, Prothrow-Stith D. Social capital, income inequality, and mortality. Am J Public Health. 1997;87: 1491-1498.

11. Kawachi I, Kennedy BP, Glass R. Social capital and self-rated health: a contextual analysis. Am J Public Health. 1999;89:1187-1193.

12. Yamaoka K. Social capital and health and well-being in East Asia: a population-based study. Soc Sci Med. 2008;66:885-899.

13. Mansyur C, Amick BC, Harrist RB, Franzini. Social capital, income inequality, and self-rated health in 45 countries. Soc Sci Med. 2008;66:43-56.

14. Drukker M, Buka S, Kaplan C, McKenzie K, Van Os J. Social capital and young adolescents' perceived health in different sociocultural settings. Soc Sci Med. 2005;61:185-198.

15. Russek LG, Schwartz GE. Perceptions of parental caring predict health status in midlife: a 35-year follow-up of the Harvard Mastery of Stress Study. Psychosom Med. 1997;59(2):144-149.

16. Kawachi I, Berkman LF. Social cohesion, social capital, and health. In: Berkman LF, Kawachi I (editors). Social Epidemiology. Oxford, UK: Oxford University Press; 2000.

17. Cattell V. Poor people, poor places, and poor health: the mediating role of social networks and social capital. Soc Sci Med. 2001;52:1501-1516.

18. Halpern DS. Minorities and mental health. Soc Sci Med; 1993;36(5): 597-607.

19. Rhodes T, Singer M, Bourgois P, Friedman SR, Strathdee SA. The social structural production of HIV risk among injecting drug users. Soc Sci Med. 2005;61:1026-1044.

20. Stack C. All Our Kin: Strategies for Survival in a Black Community. New York: Harper and Row Publishing; 1974.

21. Lewis O. Five Families: Mexican Case Studies in the Culture of Poverty. New York: Basic Books; 1959. 
22. Wilson WJ. The Truly Disadvantaged: the Inner City, the Underclass, and Public Policy. Chicago, IL: University of Chicago Press; 1987.

23. Helliwell J. How's life? Combining individual and national variables to explain subjective well-being. NBER Working Paper No. 9065 Cambridge: National Bureau of Economic Research. 2002;20(2):331-360.

24. Veenstra G. Social capital and health (plus wealth, income inequality and regional health governance). Soc Sci Med. 2003;54:849-868.

25. Holtgrave DR, Crosby RA. Social capital, poverty, and income inequality as predictors of gonorrhea, syphilis, chlamydia and AIDS case rates in the United States. Sex Transm Infect. 2003;79:62-64.

26. China Economy. Source, 2011 CIA World Factbook and other sources. Available from: http://www.theodora.com/wfbcurrent/china/ china_economy.html. Accessed May 24, 2011.

27. Chen X, Stanton B, Kaljee L, et al. Social stigma, social capital reconstruction, and rural migrants in urban China: A population health perspective. Hum Organ. 2011;70(1):22-32.

28. Wilkinson R. Unhealthy societies: the affliction of inequality. London, UK: Routledge, 1996.

29. Cozzolino PJ. Trust, cooperation, and equality: a psychological analysis of the formation of social capital. Br J Soc Psychol. 2011;50: 302-320.

30. Jessor R. Risk behavior in adolescence: a psychosocial framework for understanding and action. J Adolesc Health. 1991;12(8):597-605.

31. Kaljee LM, Green M, Riel R, et al. Sexual stigma, sexual behaviors, and abstinence among Vietnamese adolescents: implications for risk and protective behaviors for HIV, sexually transmitted infections, and unwanted pregnancy. J Assoc Nurses AIDS Care. 2007;18(2): 48-59.

32. Miller AM, Vance CS. Sexuality, human rights, and health. Health Hum Rights. 2004;7(2):5-15.

33. Mahajan AP, Sayles JN, Patel VA, et al. Stigma in the HIV/AIDS epidemic: a review of the literature and recommendations for the way forward. AIDS. 2008;22(Suppl 2):S67-S79.

34. Sontag S. Illness as Metaphor. New York: Farrar, Straus, Giroux; 1988.

35. Rosenberg CE. The Cholera Years: The United States in 1832, 1849, and 1866. Chicago, IL: University of Chicago Press; 1987.

36. MacLean L, Edwards N, Garrard M, Sims-Jones N, Clinton K, Ashley L. Obesity, stigma and public health planning. Health Promot Int. 2009;24(1):88-93.

37. Simons-Morton BG, Farhat T. Recent findings on peer group influences on adolescent smoking. J Prim Prev. 2010;31(4):191-208.

38. Brown SA, McGue M, Maggs J, et al. A developmental perspective on alcohol and youths 16 to 20 years of age. Pediatrics. 2008;121 Suppl 4 S290-S310.

39. Schulenberg JE, Maggs JL. A developmental perspective on alcohol use and heavy drinking during adolescence and the transition to young adulthood. J Stud Alcohol Suppl. 2002;14:54-70.

40. Koyama A, Corliss HL, Santelli JS. Global lessons on healthy adolescent sexual development. Curr Opin Pediatr. 2009;21(4):444-449.

41. UNAIDS. Interagency Task Team on Young People: Preventing HIV/ AIDS in Young People: A Systematic Review of the Evidence from Developing Countries. 2006.

42. Forhan SE, Gottlieb SL, Sternberg MR, et al. Prevalence of sexually transmitted infections among female adolescents aged 14 to 19 in the United States. Pediatrics. 2009;124(6):1505-1512.

43. Berlan ED, Holland-Hall C. Sexually transmitted infections in adolescents: advance in epidemiology, screening and diagnosis. Adolesc Med State Art Rev. 2010;21(2):332-346.

44. Busza J. Sex work and migration: the dangers of oversimplification, a case study of Vietnamese women in Cambodia. Health Hum Rights. 2004; 7(2):231-249.

45. Latkin CA, Forman V, Knowlton A, Sherman S. Norms, social networks and HIV related risk behaviors among urban disadvantaged drug users. Soc Sci Med. 2003;54:465-476.

46. Singer M. Toward a biocultural and political economic integration of alcohol, tobacco, and drug studies in the coming century. Soc Sci Med. 2001;53:199-213.
47. Friedman SR, Mateu-Gelabert P, Curtis R, et al. Social capital or networks, negotiations, and norms? A neighborhood case study. Am J Prev Med. 2007;32(6S): S160-S170.

48. Moreira MT, Smith LA, Foxcroft D. Social norms interventions to reduce alcohol misuse in university college students. Cochrane Database Syst Rev. 2009;8(3):CD006748.

49. Sok P, Harwell JI, Dansereau L, McGarvey S, Lurie M, Mayer KH. Patterns of sexual behavior of male patients before testing HIV-positive in a Cambodian hospital, Phnom Penh. Sex Health. 2008;5(4):353-358.

50. Hoa TD, Cohen S, Nghi NQ, et al. Behind the pleasure: Sexual decision making among high-risk men in urban Vietnam. Family Health International Report. 2006. Available from: http://www.fhi.org/NR/rdonlyres/ ebcnwsabfc5mrayzgfsrvmsp2soradptfxpvptzz2xare3ajw bumy64glmn5e633c5br5rdzua5qpo/RiskMenReportEnglish.pdf. Accessed January $3,2010$.

51. Kaljee LM, Green MS, Zhan M, et al. Gender, alcohol consumption patterns, and engagement in sexually intimate behaviors among adolescents and young adults in Nha Trang, Viet Nam. Youth Soc. 2011;43(1):118-141.

52. Tho LH, Singhasivanon P, Kaewkungwai J, Kaljee LM, Charoendul C. Sexual behaviors of alcohol drinkers and non-drinkers among adolescents and young adults in Nha Trang Vietnam. Southeast Asian J Trop Med Public Health. 2007;38(1):152-160.

53. Bartkowski JP, Xu X. Religiosity and teen drug use reconsidered: a social capital perspective. Am J Prev Med. 2007;32(6S): S182-S194.

54. Takahashi LM, Magalong MG. Disruptive social capital: (un)healthy socio-spatial interactions among Filipino men living with HIV/AIDS Health Place. 2008;14(2):182-197.

55. Campbell C, Williams B, Gilgran D. Is social capital a useful conceptual tool for exploring community-level influences on HIV infection? An exploratory case study from South Africa. AIDS Care. 2002;14(1):41-54

56. Gregson S, Terceira N, Mushati P, Nyamukapa C, Campbell C. Community group participation: can it help young women to avoid HIV? An exploratory study of social capital and school education in rural Zimbabwe. Soc Sci Med. 2004;58:2119-2132.

57. Pronyk PM, Harpham T, Morison LA, et al. Is social capital associated with HIV risk in rural South Africa? Soc Sci Med. 2008;66: 1999-2010.

58. Caughy MO, O'Campo PJ, Muntaner C. When being alone might be better: neighborhood poverty, social capital, and child mental health. Soc Sci Med. 2003;57:227-237.

59. Drukker M, Kaplan C, Feron F, Van Os J. Children's healthrelated quality of life, neighborhood socio-economic deprivation and social capital: a contextual analysis. Soc Sci Med. 2003;57: 825-841.

60. Lin D, Li X, Yang H, et al. Alcohol intoxication and sexual risk behaviors among rural-to-urban migrants in China. Drug Alcohol Depend. 2005;79:103-112.

61. Wang B, Li X, Stanton B, Fang X. The influences of social stigma and discriminatory experience on psychological distress and quality of life among rural-to-urban migrants in China. Soc Sci Med. 2010;71(1):84-92.

62. Wang B, Li X, Stanton B, Zhang L, Fang X. Alcohol use, unprotected sex, and sexually transmitted infections among female sex workers in China. Sex Transm Dis. 2010;37(10):629-636.

63. Eshetu EB, Woldesenbet SA. Are there particular social determinants of health for the world's poorest countries? Afr Health Sci. 2011;11(1):108-115.

64. Krishna A, Shrader E. Cross-Cultural Measures of Social Capital: A Tool and Results from India and Panama. Washington, DC: World Bank; 2000

65. De Silva MJ, Huttly SR, Harpham T, Kenward MG. Social capital and mental health: a comparative analysis of four low income countries. Soc Sci Med. 2007;64:5-20. 
66. De Silva MJ, Harpham T, Tuan T, Bartolini R, Penny ME, Huttly SR. Psychometric and cognitive validation of a social capital measurement tool in Peru and Vietnam. Soc Sci Med. 2006;62: 941-953.

67. Chen X, Stanton B, Gong J, Fang X, Li X. Personal social capital scale: an instrument for health and behavioral research. Health Educ Res. 2009;24:306-317.
68. Johnson BT, Scott-Sheldon LA, Huedo-Medina TB, Carey MP. Interventions to reduce sexual risk for human immunodeficiency virus in adolescents: a meta-analysis of trials 1985-2008. Arch Pediatr Adolesc Med. 2011;165(1):77-84.

69. Tripodi SJ, Bender K, Litschge C, Vaughn MG. Interventions for reducing adolescent alcohol abuse: a meta-analytic review. Arch Pediatr Adolesc Med. 2010;164(1):85-91.

\section{Publish your work in this journal}

Adolescent Health, Medicine and Therapeutics is an international, peer-reviewed, open access journal focusing on health, pathology, and treatment issues specific to the adolescent age group. All aspects of health maintenance, preventative measures and disease treatment interventions are addressed within the journal and practitioners from all disciplines are invited to submit their work as well as healthcare researchers and patient support groups.. The manuscript management system is completely online and includes a very quick and fair peerreview system. Visit http://www.dovepress.com/testimonials.php to read real quotes from published authors.

Submit your manuscript here: http://www.dovepress.com/adolescent-health-medicine-and-therapeutics-journal 